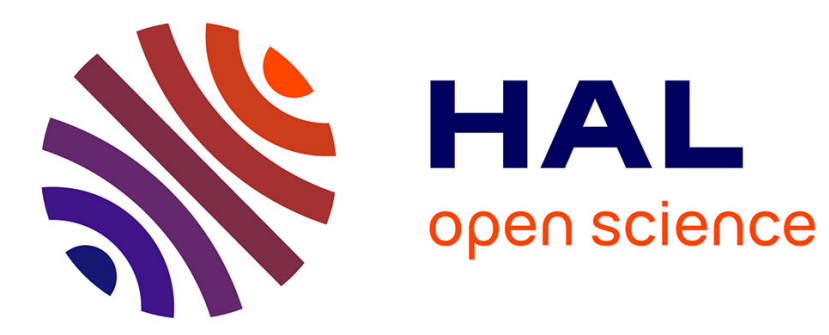

\title{
Marine Tidal Current Electric Power Generation Technology: State of the Art and Current Status
}

Seifeddine Benelghali, Mohamed Benbouzid, Jean Frédéric Charpentier

\section{To cite this version:}

Seifeddine Benelghali, Mohamed Benbouzid, Jean Frédéric Charpentier. Marine Tidal Current Electric Power Generation Technology: State of the Art and Current Status. IEEE IEMDC'07, May 2007, Antalya, Turkey. pp.1407-1412. hal-00531255

\section{HAL Id: hal-00531255 https://hal.science/hal-00531255}

Submitted on 2 Nov 2010

HAL is a multi-disciplinary open access archive for the deposit and dissemination of scientific research documents, whether they are published or not. The documents may come from teaching and research institutions in France or abroad, or from public or private research centers.
L'archive ouverte pluridisciplinaire HAL, est destinée au dépôt et à la diffusion de documents scientifiques de niveau recherche, publiés ou non, émanant des établissements d'enseignement et de recherche français ou étrangers, des laboratoires publics ou privés. 


\title{
Marine Tidal Current Electric Power Generation Technology: State of the Art and Current Status
}

\author{
S.E. Ben Elghali, Student Member, IEEE, M.E.H. Benbouzid, Senior Member, IEEE, and J.F. Charpentier, Member, IEEE
}

\begin{abstract}
The potential of electric power generation from marine tidal currents is enormous. Tidal currents are being recognized as a resource to be exploited for the sustainable generation of electrical power. The high load factors resulting from the fluid properties and the predictable resource characteristics make marine currents particularly attractive for power generation and advantageous when compared to other renewable energies. Moreover, international treaties related to climate control have triggered resurgence in development of renewable ocean energy technology. Therefore, several demonstration projects in tidal power are scheduled to capture the tidal generated coastal currents. Regarding this emerging and promising area of research, this paper reviews marine tidal power fundamental concepts and main projects around the world. It also report issues regarding electrical generator topologies associated to tidal turbines. Moreover, attempts are made to highlight future issues so as to index some emerging technologies mainly according to relevant works that have been carried out on wind turbines and on ship propellers.
\end{abstract}

Index Terms-Tidal current, marine technology, electric power generation, energy converter systems, state of the art.

\section{INTRODUCTION}

Oceans, covering more than $70 \%$ of the earth, have long been appreciated as a vast renewable energy source. The energy is stored in oceans partly as thermal energy, partly as kinetic energy (waves and currents) and also in chemical and biological products. Numerous techniques for extracting energy from the sea have been suggested, most of which can be included in one of the following categories: wave energy, marine and tidal current energy, ocean thermal energy, energy from salinity gradients (osmosis), and cultivation of marine biomass. The kinetic energy present in marine and tidal currents can be converted to electricity using relatively conventional turbine technology. To harness the kinetic energy in waves present a different set of technical challenges and a wide variety of designs have been suggested. Ocean thermal energy conversion is possible in locations with large temperature differences, extracting energy with a heat engine. Salinity gradients can be exploited for energy extraction through the osmotic process. The cultivation of marine biomass can yield many useful products, including renewable fuels for electricity generation.

This work is supported by Brest Métropole Océane (BMO) and the European Social Fund (ESF). It is done within the framework of the Marine Renewable Energy Commission of the Brittany Maritime Cluster (Pôle Mer Bretagne).

S.E. Ben Elghali and M.E.H. Benbouzid are with the Laboratoire d'Ingénierie Mécanique et Electrique (LIME), University of Western Brittany, Rue de Kergoat, BP 93169, 29231 Brest Cedex 3, France (e-mail: benelghali@univ-brest.fr, m.benbouzid@ieee.org).

J.F. Charpentier is with the French Naval Academy Research Institute (IRENav) EA 3634, French Naval Academy, Lanveoc-Poulmic, BP 600, 29240 Brest Armées, France (e-mail: charpentier@ecole-navale.fr).
However, due to technology limitations and economic considerations, osmotic and thermal energy developments are limited [1-3].

Only a fraction of the global ocean energy resource can be found in sites economically feasible to explore with the available technology. However, this fraction could still make a considerable contribution to electricity supply. This is the reason why the marine renewable sector is currently the focus of much industrial and academic research around the world [4-5]. Sites with attractive wave climate and intense tidal currents are abundant in the vicinity of the European coastline. It has been shown that $48 \%$ of the European tidal resource is in the UK, $42 \%$ in France, and $8 \%$ in Ireland [6]. There are basically two ways of generating electricity from marine and tidal currents: by building a tidal barrage across an estuary or a bay in high tide areas, or by extracting energy from free flowing water (tidal kinetic energy).

A tidal barrage applies the same principles as hydro-electric power generation, except that tides flow in both directions and generators are designed to respond to two directional water flows. The simplest generating system for tidal plants is the ebb generating system (Fig. 1), which involves a dam, known as a barrage across a bay or estuary. Sluice gates on the barrage allow the tidal basin to fill on the incoming high tides and to exit through the turbine system on the outgoing tide (known as the ebb tide). La Rance tidal power plant, generating $240 \mathrm{MW}$, is the largest operating tidal facility in the world, far bigger than the next largest, the Annapolis facility (20 MW) in Canada. The enclosed estuary of La Rance River in Brittany (France) has a surface area of $22 \mathrm{~km}^{2}$ (Fig. 2) and very large tides with $13.5 \mathrm{~m}$ difference between high and low tides during the equinox. There are 24 units of $10 \mathrm{MW}$ which can run during both incoming and outgoing tides [7-8].

Within the last few decades, developers have shifted towards technologies that capture the tidally-driven coastal currents or tidal stream. Indeed, very large amount of energy are available in coastal waters [1], [9-15]. There are many areas of the world in which extreme tidal currents are observed. Three examples in France are shown in Fig. 3. The Raz Blanchard situated in Cap de la Hague experiences extreme tidal currents exceeding 8 knots and leading to a large amount of kinetic energy flux.

Regarding this emerging and promising area of research, this paper will review marine tidal power fundamental concepts and main projects around the world.

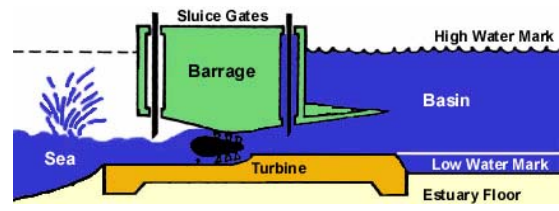

Fig. 1. Ebb generating system with a bulb turbine. 


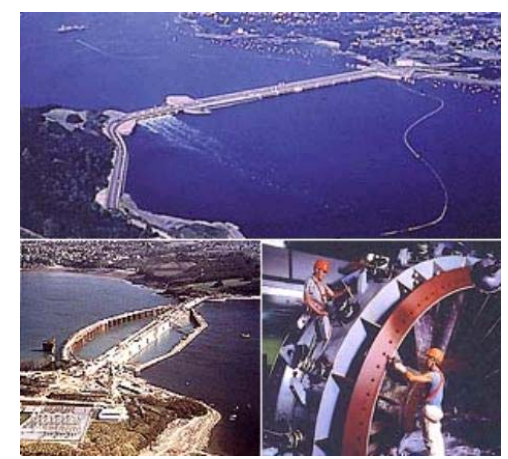

Fig. 2. La Rance tidal power station [6].

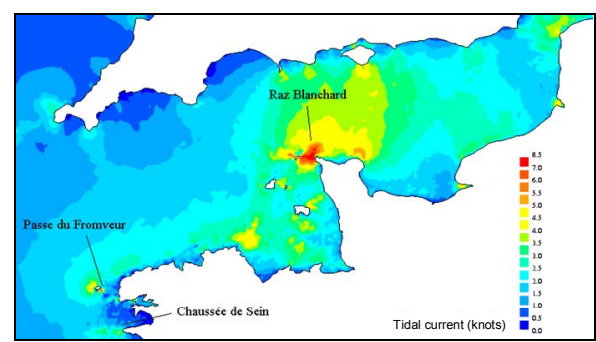

Fig. 3. Raz Blanchard, Fromveur, and Raz de Sein and sites in the French western coast.

It will also report issues regarding electrical generator topologies associated to tidal turbines. Moreover, attempts will be made to highlight future issues so as to index some emerging technologies mainly according to relevant works that have been carried out on wind turbines and on ship propellers.

\section{TIDAL KINETIC ENERGY BACKGROUND}

The attractions of tidal currents to renewable energy developers are obvious. The medium, seawater, is more than 800 times denser than air and the astronomic nature of the underlying driving mechanism results in an essentially predictable resource, although subject to weather-related fluctuations.

As a renewable resource, tidal current flow is very predictable, to within $98 \%$ accuracy for decades. Tidal charts are accurate to within minutes, for years ahead. Tidal current is independent of prevailing weather conditions such as wind, fog, rain, and clouds that can impact other renewable generation forecasts. Solar generation is impacted by rain, clouds and fog. Wind turbines are impacted by calm weather, yet tidal cycles are as reliable as the rising of the moon. While solar and wind are valuable renewable resources, neither can be plotted with the predictability of tidal energy. Thus, reliable amounts of tidal power can be forecast with confidence. This predictability is critical to successful integration of renewable resources into the electrical grid [9].

\section{A. Tidal Resource}

The global marine current energy resource is mostly driven by the tides and to a lesser extent by thermal and density effects. The tides cause water to flow inwards twice each day (flood tide) and seawards twice each day (ebb tide) with a period of approximately 12 hours and 24 minutes (a semi-diurnal tide), or once both inwards and seawards in approximately 24 hours and
48 minutes (a diurnal tide). In most locations the tides are a combination of the semi-diurnal and diurnal effects, with the tide being named after the most dominant type. The strength of the currents varies, depending on the proximity of the moon and sun relative to earth. The magnitude of the tide-generating force is about $68 \%$ moon and $32 \%$ sun due to their respective masses and distance from earth. Where the semi-diurnal tide is dominant, the largest marine currents occur at new moon and full moon (spring tides) and the lowest at the first and third quarters of the moon (neap tides). With diurnal tides, the current strength varies with the declination of the moon (position of the moon relative to the equator). The largest currents occur at the extreme declination of the moon and lowest currents at zero declination. Further differences occur due to changes between the distances of the moon and sun from earth, their relative positions with reference to earth and varying angles of declination. These occur with a periodicity of two weeks, one month, one year or longer, and are entirely predictable [6], [16].

The resource assessment is generally based on oceanographic databases containing data with a fixed grid square resolution. The main key criteria are: maximum spring current velocity; maximum neap current velocity; seabed depth; maximum probable wave height in 50 years; seabed slope; significant wave height; and the distance from land [12], [17-18]. For illustration, Fig. 4 shows tidal velocity in the Raz de Sein (France) for the year 2007 and March 2007.

\section{B. Kinetic Energy Extraction}

The total kinetic power in a marine current turbine has a similar dependence as a wind turbine and is governed by the following equation [6], [19-20]

$$
P=\frac{1}{2} \rho A v^{3}
$$

where $\rho$ is the fluid density, $A$ is the cross-sectional area of the turbine and $V$ is the fluid velocity.
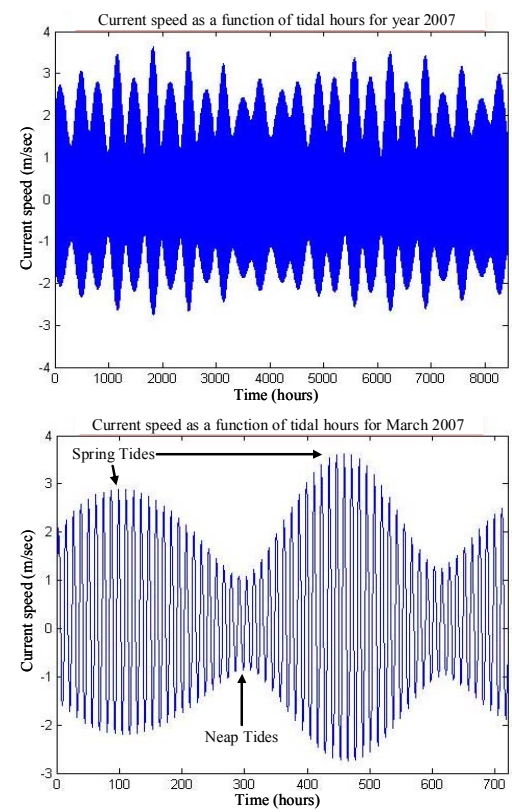

Fig. 4. Tidal velocity in the Raz de Sein for the year 2007 and March 2007. 
However, a marine energy converter or turbine can only harness a fraction of this power due to losses and (1) is modified as follows

$$
P=\frac{1}{2} \rho C_{p} A v^{3}
$$

$C_{p}$ is known as the power coefficient and is essentially the percentage of power that can be extracted from the fluid stream and takes into account losses due to Betz law and those assigned to the internal mechanisms within the converter or turbine. For wind generators, $C_{p}$ has typical values in the range $0.25-0.3$. The upper limit is for highly efficient machines with low mechanical losses. For marine turbines, $C_{p}$ is estimated to be in the range $0.35-0.5$ [21].

Compared to the largest wind turbines operating today, the power output as well as the size of a classical tidal turbine are extremely promising. For illustration, Fig. 5 shows a tidal turbine against an offshore wind turbine of the same power rating. Furthermore, with constant or highly predictable marine currents a tidal turbine could not only rival the largest wind turbines in being more manageable in size but also in generating highly predictable power [20], [22].

\section{TURBINE TECHNOLOGIES AND CONCEPTS}

The harnessing of the energy in a tidal flow requires the conversion of kinetic energy in a moving fluid, in this case water, into the motion of a mechanical system, which can then drive a generator. It is not too surprising, therefore, that many developers propose using technology that mirrors that which has been successfully utilized to harness the wind, which is also a moving fluid. Therefore, most devices can be characterized as belonging to three fundamental types [23]. These are (Fig. 6):

- Horizontal axis systems that has been installed in the Bristol Channel between England and Wales [24], or in Hammerfest Strøm, in Norway [25].

- Vertical axis systems such as the device that was tested in the Strait of Messina between Sicily and the Italian mainland [26].

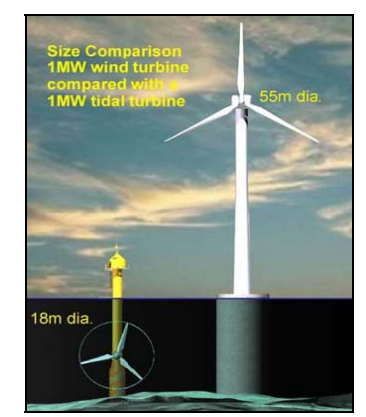

Fig. 5. Tidal turbine against an offshore wind turbine [C MCT].

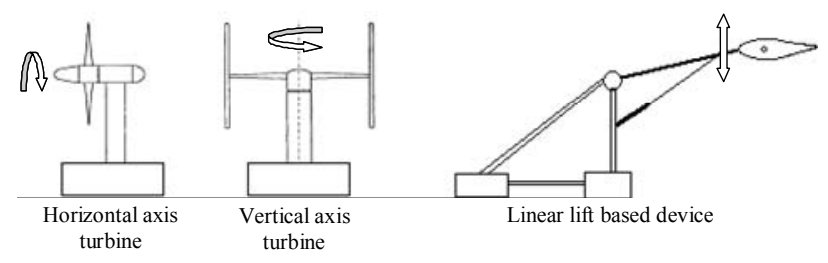

Fig. 6. Tidal turbine fundamental types.
- Variable foil systems such as the device that has been tested in Yell Sound in Shetland, which lies to the North of Scotland and Orkney [27].

In the following is presented an overview of some of the major tidal turbine technologies and concepts.

\section{A. Horizontal Axis Turbines}

1) The Marine Current Turbine (MCT) Projects (UK) [24]. Figure 7 shows hybrid illustrations of the Seaflow turbine. It has a single $11 \mathrm{~m}$ diameter rotor, with full span pitch control, and is installed in a mean depth of seawater of $25 \mathrm{~m}$ approximately 1.1 $\mathrm{km}$ off the nearest landfall at the Foreland Point lighthouse below Exmoor in North Devon, UK. It has exceeded its $300 \mathrm{~kW}$ rated power under favorable flow conditions with a $15 \mathrm{rpm}$ rotor speed. It is not grid-connected but as an experimental test-rig dumps its power into resistance heaters capable of absorbing the maximum power. A key feature is that it is mounted on a steel tubular pile, $2.1 \mathrm{~m}$ in diameter, set in a hole drilled in the seabed and tall enough to always project above the surface of the sea. The entire rotor and power system can be physically raised up the pile above the surface to facilitate maintenance or repairs from a boat, a vital requirement as the use of divers or any other form of underwater intervention is virtually impossible in locations with such strong currents.

MCT second project was Seagen. The Seagen turbine has its rotors mounted at the outer ends of a pair of streamlined wing-like arms projecting either side of the supporting pile (Fig. 8a). Each rotor drives a power-train consisting of a gearbox and generator each rated at around $500 \mathrm{~kW}$. The total rated power is approximately $1 \mathrm{MW}$. Essentially the Seagen turbine produces three times the power of Seaflow. The Seagen project will be followed by an array of similar systems (farm) to be installed in an open sea location. Three turbines will be added to provide a total capacity up to $5 \mathrm{MW}$ (Fig. 8b).

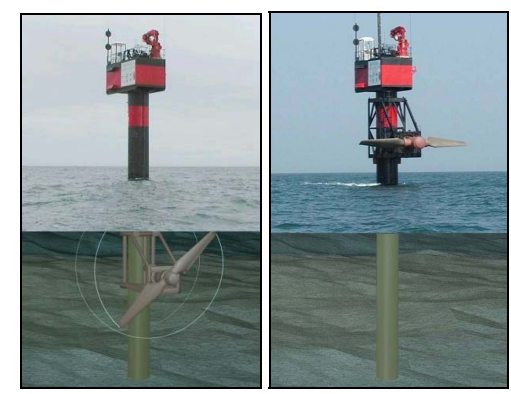

Fig. 7. Hybrid illustration of the Seaflow turbine [C MCT].

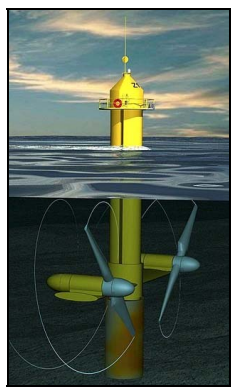

(a) Seagen turbine.

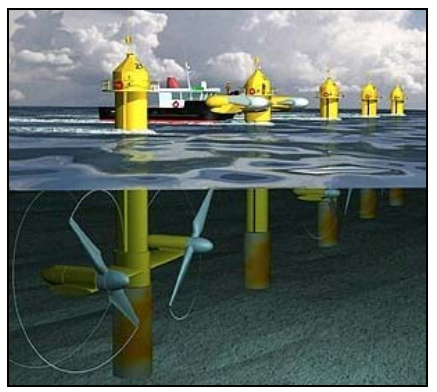

(b) Seagen farm
Fig. 8. The Seagen system illustration [C MCT]. 
2) The E-Tide Project (Norway) [25]. Hammerfest Strøm has developed the so-called Blue or E-Tide Concept in Kvalsund (Northern Norway) in 2003. The Blue Concept device is a tidal current turbine that can be installed on the seabed offshore or near shore depending on the tidal current strength (Fig. 9). A 300 $\mathrm{kW}$ system was tested and the concept proven during the installation and a larger design is being developed for the same location that will provide $750-1000 \mathrm{~kW}$ of power. The turbine blades of 15-16 m are able to rotate on their own axes, allowing the turbine to be optimized to current conditions and also operate in both directions of the tide (pitch control).

3) The Tidal Stream Energy Project (UK) [28]. The Tidal Stream turbine is shown in Fig. 10. This configuration is designed for the site of Pentland Firth between the North of Scotland and the Orkney Islands [18]. In the first design (Fig. 10a), the twin turbine carries two $20 \mathrm{~m}$ rotors, is rated at $1-2$ MW depending on current speed, and operates in 30-50 m water depths. Each rotor runs in clean water upstream of its support arm. The seabed anchorage is now shown with a gravity base, and the swinging arm ball-joint is attached to the base by a three-axis swivel assembly. The swinging arm is hinged at its upper end to the main spar buoy so that it can be stowed easily for installation/removal. During operation it is held in place by a cranked strut. In today's design of Pentland Firth turbine (Fig. 10b), the $60 \mathrm{~m}$ deep water flow is covered by four $20 \mathrm{~m}$ rotors rather than a pair, in order to keep blade loads within practical limits. The whole turbine power output is 4 MW. Once rolled over into its maintenance position, the main swing-arm can be stowed for float-out removal/installation.

4) The SMD Hydrovision TidEL Project (UK) [29]. The TidEl concept consists of a pair of contra-rotating $500 \mathrm{~kW}$ turbines, mounted together on a single crossbeam (Fig. 11). The complete assembly is buoyant and tethered to the seabed by a series of mooring chains. The mooring system allows the turbines to align themselves down stream of the prevailing tidal flow without requiring any external intervention. As the system requires no support structure, it can be fitted in any reasonable coastal water depth. Each of the turbine powertrains are driven by $15 \mathrm{~m}$ diameter fixed pitched blades and are housed within a pod. The $1 \mathrm{MW}$ units are designed to be mounted in an offshore tidal environment with a peak tidal velocity of 5 knots $(2.5 \mathrm{~m} / \mathrm{sec})$ or more and a water depth of greater than $30 \mathrm{~m}$.

5) The Lunar Energy Project (UK) and the HydroHelix Energies Project (France) [30-31]. These systems feature a ducted turbine, fixed to the seabed via gravity foundation. In principle, the duct captures a large area of the tidal stream and accelerates the flow through a narrowing channel into the turbine. Thus, a smaller turbine can be used for a given power output, or alternatively, a larger amount of power can be generated by a turbine of given blade diameter. The Lunar Energy tidal turbine is of a symmetrical design and capable of bi-directional operation obviating the need for a pitch or yaw control thus keeping the design simple and more cost effective (Fig. 12). The tidal flow can be offset by as much as 40 degrees to the duct axis without affecting the performance. A 1/20th model was tested in 2004, and a 1 MW prototype is expected soon.

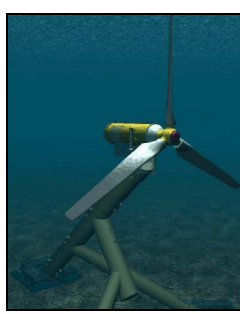

(a) E-tide turbine.

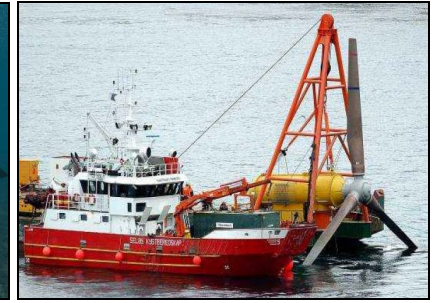

(b) Installation.
Fig. 9. The Blue or E-Tide concept [C Strøm AS].

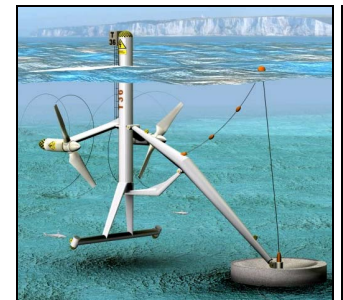

(a)

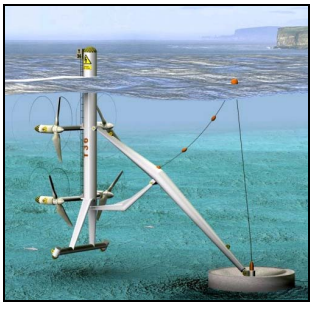

(b)
Fig. 10. The Tideal Stream concept [@ Tidal Stream].
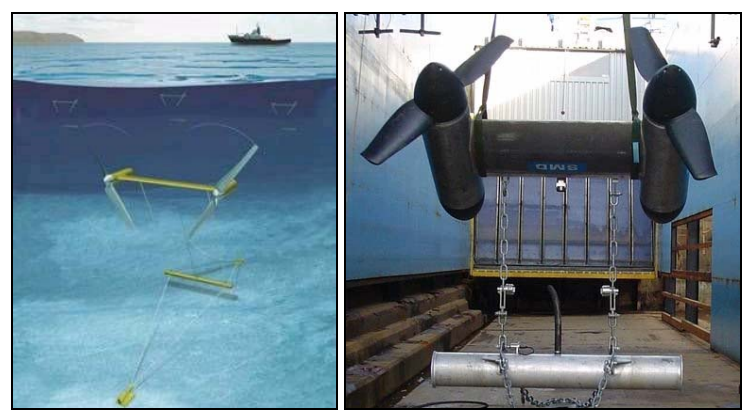

Fig. 11. Illustration and front view of the TidEL turbine [@ SMD Hydrovision].

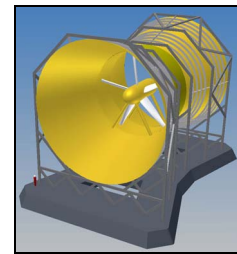

(a) Lunar turbine.

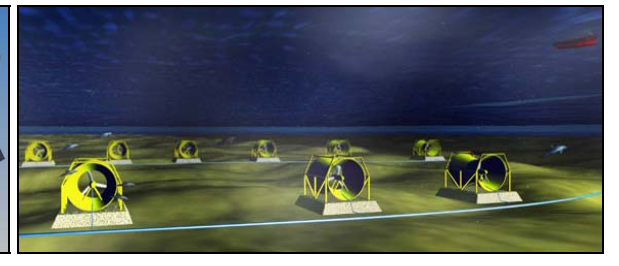

(b) Lunar farm.

Fig. 12. The Lunar Energy system illustration [@ Lunar Energy].

A similar project is the HydroHelix one in France. It consists in a $200 \mathrm{~kW}$ turbine as shown in Fig. 13a. The expected tidal energy unit is illustrated by Fig. 13b with an average output power of $1 \mathrm{MW}$.

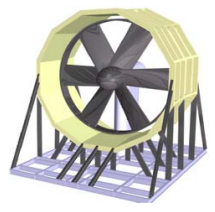

(a) HydroHelix turbine.

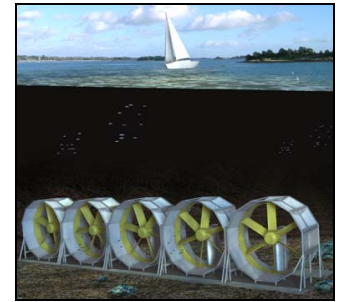

(b) HydroHelix tidal energy unit.
Fig. 13. The HydroHelix system illustration [® HydroHelix Energies]. 


\section{B. Vertical Axis Turbines}

Vertical axis turbines that operate in marine currents are based on the same principles as the land based Darrieus turbine. The Darrieus turbine is a cross flow machine, whose axis of rotation meets the flow of the working fluid at right angles. In marine current applications, cross flow turbines allow the use of a vertically orientated rotor which can transmit the torque directly to the water surface without the need of complex transmission systems or an underwater nacelle. The vertical axis design permits the harnessing of tidal flow from any direction, facilitating the extraction of energy not only in two directions, the incoming and outgoing tide, but making use of the full tidal ellipse of the flow [32]. In this kind of turbines as in the horizontal axis ones the rotation speed is very low (around $15 \mathrm{rpm}$ ).

1) The Enermar Project (Italy) [26]. The core of the Enermar project is the patented Kobold turbine (Fig. 14a). Among its main characteristics, the Kobold turbine has a very high starting torque that makes it able to start spontaneously even in loaded conditions. A pilot plant is moored in the Strait of Messina, close to the Sicilian shore in Italy, in an average sea tidal current of about $2 \mathrm{~m} / \mathrm{sec}$ (Fig. 14b). With a current speed of about $1.8 \mathrm{~m} / \mathrm{sec}$, the system can produce a power of $20 \mathrm{~kW}$.

2) The Blue Energy Project (Canada) [33]. Four fixed hydrofoil blades of the Blue Energy tidal turbine are connected to a rotor that drives an integrated gearbox and electrical generator assembly (Fig. 15 a). The turbine is mounted in a durable concrete marine caisson which anchors the unit to the ocean floor, directs flow through the turbine further concentrating the resource supporting the coupler, gearbox, and generator above it. These sit above the surface of the water and are readily accessible for maintenance and repair (Fig. 15b). The hydrofoil blades employ a hydrodynamic lift principal that causes the turbine foils to move proportionately faster than the speed of the surrounding water. The rotation of the turbine is unidirectional on both the ebb and the flow of the tide. A unit turbine is expected to be about $200 \mathrm{~kW}$ output power. For large scale power production, multiple turbines are linked in series to create a tidal fence across an ocean passage or inlet.

3) The Gorlov Helical Turbine (USA) [34]. The Gorlov Helical Turbine (GHT) is shown in Fig. 16a. The turbine consists of one or more long helical blades that run along a cylindrical surface like a screw thread, having a so-called airfoil or airplane wing profile. The blades provide a reaction thrust that can rotate the turbine faster than the water flow itself. The GHT is self-starting and can produce power from water current flow as low as $1.5 \mathrm{~m} / \mathrm{sec}$ with power increasing in proportion to the water velocity cubed. Due its axial symmetry, the GHT always rotates in the same direction, even when tidal currents reverse direction. This is a very important advantage that simplifies design and allows exploitation of the double action tidal power plants. The standard model $(1 \mathrm{~m}$ in diameter, $2.5 \mathrm{~m}$ in length) can be installed either vertically or horizontally to the water current flow [35]. A single GHT rated power is 1.5 $\mathrm{kW}$ for $1.5 \mathrm{~m} / \mathrm{sec}$ water speed and $180 \mathrm{~kW}$ for $7.72 \mathrm{~m} / \mathrm{sec}$. A pictorial view of a floating tidal power plant with two vertically aligned triple-helix turbines is shown in Fig. 16b.

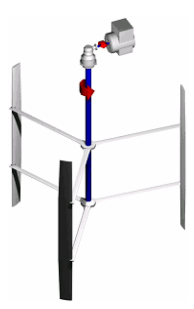

(a) Kobold turbine.

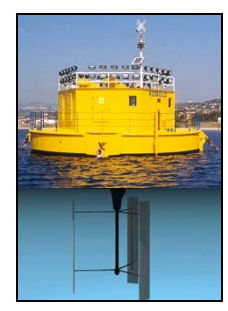

(b) Floating platform
Fig. 14. The Enermar project [C Ponte di Archimede].

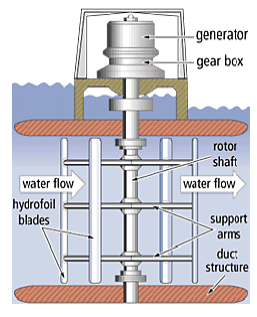

(a) Blue Energy turbine.

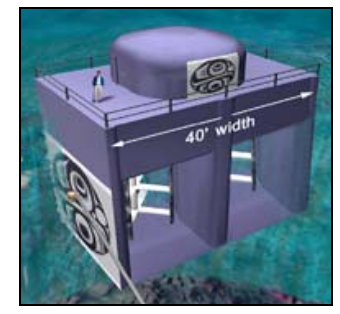

(b) Turbine platform.
Fig. 15. The Blue Energy project [C Blue Energy].

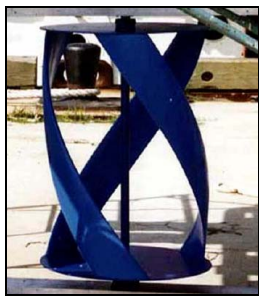

(a) Gorlov turbine.

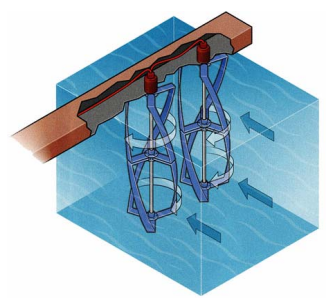

(b) Expected power plant
Fig. 16. The Gorlov helical turbine [C GCK Technology]

\section{Oscillating Hydrofoil [27]}

The Stingray concept, developed by Engineering Business (UK), is illustrated by Fig. 17a. It consists of a hydroplane that has an attack angle relative to the approaching water stream varied by a simple mechanism. This causes the supporting arm to oscillate, which in turn forces hydraulic cylinders to extend and retract. This produces high-pressure oil that is used to drive a generator. The $150 \mathrm{~kW}$ rated demonstrator produced $250 \mathrm{~kW}$ at peak capacity and averaged $90 \mathrm{~kW}$ in a $1.5 \mathrm{~m} / \mathrm{sec}$ measured current during its initial (Fig. 17b) power cycles.

\section{ELECTRIC GENERATORS TOPOLOGIES}

Much of the technology that has been suggested for tidal current energy extraction is reminiscent of that used for wind application. It is then obvious that some of wind electric generator topologies could be used for tidal turbine [36]. In [36], many topologies seem to be exploitable for tidal turbines.

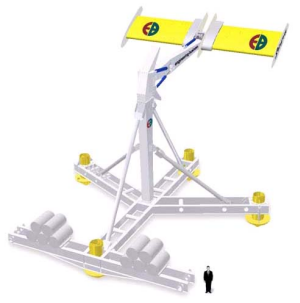

(a) The Stingray turbine.

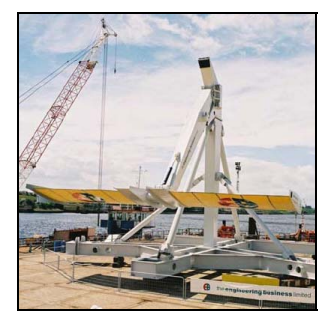

(b) Deployment for submerged testing.
Fig. 17. The Stingray tidal turbine [C EB]. 
For illustration, the Uldolmok (the strait of the strongest tidal current in Korea, located at the southwestern tip of the Korean Peninsula) pilot tidal current power plant of 1MW uses Gorlov Helical Turbine and two generator topologies: a doubly-fed induction generator $(500 \mathrm{~kW})$ and a synchronous generator $(500 \mathrm{~kW})$ [37].

Furthermore, one should distinguish two topology categories: the direct and the indirect driven technology. In tidal turbine application, maintenance is a key feature and sometimes it is considered as a barrier to marine turbine development [20]. It is then recommended to avoid gearbox systems that need regular lubrication and induce additional losses. In this context, direct driven generators are an alternative solution. In spite of the similarities with wind turbines, tidal ones present some distinct features such as the blade reduced diameter (Fig. 5) and maintenance difficulties. These characteristics will push ahead some topologies that are not commonly used for wind turbines. The vertical axis turbine with a synchronous generator is one of these technologies. An advantage of this topology is that the generator can be located under or upper the tidal turbine. That means that the size of the generator is not constraint by the turbine.

The rim tidal turbine is another technology that can be used to extract tidal current energy [38]. The rim turbine, with just one moving part and no seals, is a self-contained rotor with a solid state permanent magnet generator encapsulated within the outer rim, minimizing maintenance requirements. This concept has been adopted by OpenHydro (Ireland) through their OpenCentre Turbine that is shown by Fig. 18 [39].

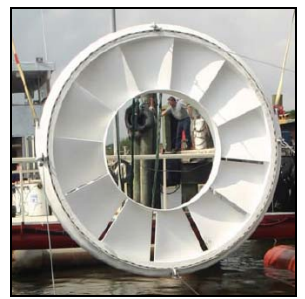

Fig. 18. The Open-Centre Turbine [ $\odot$ OpenHydro].

\section{SUMMARY}

This paper has review the state of art of marine tidal turbines. The emphasis has been put on tidal turbine concepts. Indeed, it has been described the strength and the weakness of the major tidal turbine technologies. Moreover, attempts have been made to highlight current trends and alternative issues for generator topologies.

\section{REFERENCES}

[1] A.T. Jones et al., "Recent progress in offshore renewable energy technology development," in Proceedings of IEEE PESGM'05, vol. 2, pp. 2017-2022, San Francisco (USA), June 2005.

[2] R. Ramakumar et al., "Economic aspects of advanced energy technologies," Proc. IEEE, vol. 3, n8, pp. 318-332, March 1993.

[3] G.T. Heydt, "An assessment of ocean thermal energy conversion as an advanced electric generation methodology," Proc. IEEE, vol. 3, n8, pp. 409-418, March 1993.

[4] C.M. Johnstone et al., "EC FPVI co-ordinated action on ocean energy: A European platform ford sharing technical information and research outcomes in wave and tidal energy systems," Renewable Energy, vol. 31, pp. 191-196, 2006.
[5] L.B. Bernshtein, "Tidal power development - A realistic, justifiable and topical problem of today," IEEE Trans. Energy Conversion, vol. 10, n³, pp. 591-599, September 1995.

[6] T.J. Hammons, "Tidal power," Proc. IEEE, vol. 3, n8, pp. 419-433, March 1993.

[7] S. Seth et al., "Tidal energy in electric power systems," in Proceedings of IEEE PESGM'05, vol. 2, pp. 630-635, San Francisco (USA), June 2005.

[8] J.P. Frau, "Tidal energy: Promising projects. La Rance, a successful industrial-scale experiment," IEEE Trans. Energy Conversion, vol. 8, n³, pp. 552-558, September 1993.

[9] 2005 IEEE Power Engineering Society General Meeting Panel Session, "Harnessing the untapped energy potential of the oceans: Tidal, wave, currents and OTEC," San Francisco (USA), June 2005.

[10] Technomare SpA and IT Power Ltd., "Non Nuclear Energy-JOULE II, Wave energy project results: The Exploitation of tidal marine currents,' Non-Nuclear Energy R\&D Component, EU JOULE Contract JOU2-CT94$0355,1996$.

[11] P.W. Ullman, "Offshore tidal power generation - A new approach to power conversion of the oceans' tides," MTS Journal, vol. 36, n²4, pp. 16-24, 2002.

[12] I.G. Bryden et al., "Choosing and evaluating sites for tidal current development," Proc. IMechE, Part A: Journal of Power and Energy, vol. 218, n8, pp. 567-578, 2004.

[13] B.V. Davis, "Low head tidal power: A Major source of energy from the world's oceans," in Proceedings of IECEC'97, vol. 3, pp. 1982-1989, Honolulu (USA), July-August 1997.

[14] I.G. Bryden et al., "An assessment of tidal streams as energy sources in Orkney and Shetland," Underwater Technology, vol. 21, n², 1995.

[15] I.G. Bryden, "Tidal stream power for Orkney and Shetland?," Underwater Technology, vol. 9, n4, 1993.

[16] T.G. Pugh, Tides, Surges and Mean Sea-Level. London, UK: Wiley, 1987.

[17] L.S. Bluden et al., "Initial evaluation of tidal stream energy resources at Portland Bill, UK," Renewable Energy, vol. 31, pp. 121-132, 2006.

[18] I.G. Bryden et al., "Assessing the potential of a simple tidal channel to deliver useful energy," Applied Ocean Research, vol. 26, pp. 198-204, 2004.

[19] J.S. Couch et al., "Tidal current energy extraction: Hydrodynamic resource characteristics," Proc. IMechE, Part M: Journal of Engineering for the Maritime, vol. 220, n4, pp. 185-194, 2006.

[20] A.S. Bahaj et al., "Fundamentals applicable to the utilisation of marine current turbines for energy production," Renewable Energy, vol. 28, pp. 2205-2211, 2003

[21] L. Myers et al., "Power output performance characteristics of a horizontal axis marine current turbine," Renewable Energy, vol. 31, pp. 197-208, 2006.

[22] P.L. Fraenkel, "Power from marine currents," Proc. IMechE, Part A: Journal of Power and Energy, vol. 216, n¹, pp. 1-14, 2002.

[23] I.G. Bryden et al., "ME1 - Marine energy extraction: Tidal resource analysis," Renewable Energy, vol. 31, pp. 133-139, 2006.

[24] http://www.marineturbines.com/home.htm (last accessed January 2007).

[25] http://www.e-tidevannsenergi.com/ (last accessed January 2007).

[26] http://www.pontediarchimede.com/ (last accessed January 2007).

[27] http://www.engb.com/ (last accessed January 2007).

[28] http://www.teleos.co.uk/Home.htm (last accessed January 2007).

[29] http://www.smdhydrovision.com/ (last accessed January 2007).

[30] http://www.lunarenergy.co.uk/ (last accessed January 2007).

[31] http://www.hydrohelix.fr/ (last accessed January 2007).

[32] S. Kiho et al., "The power generation from tidal currents by Darrieus turbine," Renewable Energy, vol. 9, n¹-4, pp. 1242-1245, 1996.

[33] http://www.bluenergy.com/ (last accessed January 2007).

[34] http://www.gcktechnology.com/GCK/ (last accessed January 2007).

[35] A.M. Gorlov, "The Helical Turbine and its applications for tidal and wave power," in Proceedings of IEEE OCEANCS'03, vol. 4, pp. 1996, San Diego (USA), September 2003.

[36] M.E.H. Benbouzid et al., "The state of the art of generators for wind energy conversion systems," in Proceedings of ICEM'06, Chania (Greece), September 2006.

[37] J.W. Park et al., "Wide speed operation of a doubly-fed induction generator for tidal current energy," in Proceedings of IEEE IECON'04, vol. 2, pp. 1333-1338, Busan (Korea), November 2004.

[38] S.M. Abu Sharkh et al., "Performance of an integrated water turbine pm generator," in Proceedings of IEE PEMD'02, vol. 2, pp. 486-491, Bath (UK), April 2002

[39] http://www.openhydro.com/home.html (last accessed January 2007). 